\title{
Users' Views on the Online Appointment System and Services Rendered at the Health Centre of the University of Technology, Jamaica
}

\author{
Cynthia Onyefulu1 ${ }^{*}$, Marlene Pottinger Gyles ${ }^{2}$, Leslie Meade ${ }^{2}$ \\ ${ }^{1}$ Faculty of Education \& Liberal Studies, University of Technology, Jamaica \\ ${ }^{2}$ University Health Centre, University of Technology, Jamaica \\ Email: *conyefulu@gmail.com
}

How to cite this paper: Onyefulu, C., Gyles, M.P. and Meade, L. (2018) Users' Views on the Online Appointment System and Services Rendered at the Health Centre of the University of Technology, Jamaica. Open Access Library Journal, 5: e4903. https://doi.org/10.4236/oalib.1104903

Received: September 14, 2018

Accepted: October 8, 2018

Published: October 11, 2018

Copyright $\odot 2018$ by authors and Open Access Library Inc.

This work is licensed under the Creative Commons Attribution International License (CC BY 4.0).

http://creativecommons.org/licenses/by/4.0/

(c) (i) Open Access

\begin{abstract}
The online appointment system at the university health centre was introduced by the University of Technology (UTech), Jamaica management in 2014. The purpose of this study was to determine the users' views of the online appointment system, as well as their views about the services offered at the university health centre. To achieve this purpose, a descriptive research design was used to answer three research questions. The convenience sampling method was used to select 50 participants (30 students \& 20 university staff members), who visited and used the health centre services. A questionnaire with an internal consistency of 0.87 was used to collect data from the participants who gave their consent. The findings showed that a majority of those who used the online appointment system were satisfied. The general view of the users about the health services provided at the health centre was positive. The results of the Fisher Exact test showed that there were differences in the views of the students and the staff in their responses to two items that measured the services provided by the doctors, and the access to the different services. Recommendations were made on how to improve the online appointment system as it relates to timing, and quality of services provided.
\end{abstract}

\section{Subject Areas \\ Public Health}

\section{Keywords}

Online Appointment System, Health Services, University Health Centre

\section{Introduction}

Outpatient health care centers have been around in different settings for several 
years. One of these settings is within the campus of institutions of higher learning. In some institutions, the health care centre is designed to provide general outpatient care and programmes such as health education and counselling for staff and students. At times, some of the users demand better operational management due to lack of quality service. This has led to empirical studies being done to address patients' complaints on waiting time, online appointment (scheduling) system, expectations, and improving the quality of services offered; others focus mainly on patient satisfaction. The term appointment was defined by Mardiah and Basri [1] as "the period of time allocated in the schedule to a particular patient's visit” (p. 29).

A number of studies have been done on scheduling (e.g. [2] [3]), just to name a few. Daily scheduling has been said to improve the "capacity utilisation by letting providers to fit appointment of varying length in a daily schedule, by which providers can take care of deviations from planned clinic time and scheduled appointments" [2] (p. 72). It is stated that the "overall goal of a well-designed appointment system is to achieve a balance among the competing and conflicting goals of minimizing the patient time and the doctor's idle time and overtime" [3] (p. 682). A well-designed scheduling system would contain "three types of decisions: appointment rule, patient classification, and adjust for no-show and walk-in" [2] (pp. 72-73). This allows for good quality care. Quality care is seen as the "central dimensions of public health" [4] (p. 61). Furthermore it is stated that "Good quality care needs to be delivered at the earliest and at the proper time which is [the] basic right of consumers" [4] (p. 61).

The online appointment system is "a win-win solution for patients and physicians..." [5] (p. 6). This view was also expressed by others [6]. This may be one of the reasons why there are several studies about the online or web-based appointment system. For instance, in a retrospective study of a web-based appointment system (WAS) and the queuing method in China, the authors concluded that the patients using the WAS had a higher level of satisfaction with registration when compared to those who use the queuing method who experienced a longer waiting time [7]. These authors also stated that approximately $53 \%$ of the participants did not use the online appointment service because they were unaware of its existence. For this reason, they recommended the need to better promote the use of the WAS among the patients [7]. Another study in a hospital in Norway, how the standards inscribed in an electronic booking project works was examined by combining two social theories (actor-network theory, \& the theory of collective action) [8]. The authors concluded that in certain conditions such as when the patients' problems are unclear, the use of traditional and the electronic systems booking would be better [8].

In a different study in India, the authors concluded that although the appointment system has several benefits, it is also affected by several factors such as the "arrival and service time variability, patient and provider preferences, available information technology, and the experience level of the scheduling staff" [9] (p. 21). However, the online scheduling, they stated, has more advan- 
tages when compared to the traditional appointment system. According to these authors, in the traditional appointment system, the scheduling is done by coming into the facility and the waiting time tends to be reasonably long [9]. The waiting time is minimised with the online appointment system. They also stated that the online scheduling system provides the following benefits, namely,

- Schedule patients for various medical procedures-test, treatment,

- View daily, weekly, monthly patient schedule,

- Create patient records and appointment reports,

- Helps to track patient flow based on arrival, visit and departure time,

- Avoid no-show missing, over-booking patients and other conflicts,

- Email appointment schedule reminder,

- Provide daily appointment scheduling reports. [9] (p. 26).

A similar set of benefits were also identified by [10] who also described six different types of appointment scheduling (double booking, like visits together, ten minutes increments, modified wave scheduling, staggered starts, \& group meetings) used in hospitals. For details, see [10].

In another study, [5] examined the online booking system in hospitals in Iran. Their study showed that $52.8 \%$ of the hospitals still used the in-person appointment method, while $47.2 \%$ used the remote methods (SMS, call, internet, call-SMS, \& call internet), with only $13.0 \%$ of the hospitals using the online appointment method. Samadbeik et al., [5] concluded that the traditional (inperson) method was mostly used despite the waiting time disadvantage. Using a mixed methods approach, Pare, Trudel, and Forget [6] examined the impact of e-booking in private medical practices in Canada over a two-year period. Their findings showed that there is an increased interest in the use of this system in Canada. Their findings also revealed that the users were appreciative of the system due to its benefits (flexibility in scheduling, time-saving, \& automated reminders). With all the growing popularity, many persons are still not using the online scheduling system. The results of a study done in China by Zhang, Zhang, Sun, Cai, Yang, and Zhang [11] revealed that only 17\% of the patients surveyed used the web-based system, and most patients used the queuing method.

Apart from scheduling, the literature shows that patient satisfaction by measuring quality care has gained a lot of attention as scholars try to identify gaps that can be addressed in order to improve health care services. Patient satisfaction means "the extent to which general health care needs of the clients are met to their requirements" [4] (p. 59). Among the studies on patient satisfaction, Sadjadian, Kaviani, Yunesian, and Montazeri [12] conducted a study involving 425 women in a breast cancer care clinic in Iran. Their study showed that $82 \%$ of these women were either satisfied or very satisfied with the clinic's overall performance. In a study conducted in India with 200 patients, Panda, Sinha, and Soni [13] reported that $56 \%$ of the participants were satisfied with the services at an out-patient department. Other scholars including [4] [14] [15] conducted similar studies in different countries. In a study in India with 400 patients, [15] found out that a majority of the patients were satisfied with the facilities availa- 
ble as well as the attitude of the doctors and other health staff of the hospital. On the contrary, a study done in Jordanian hospitals, Al-Refaie [16] revealed that service quality (admissions, registration, waiting time, and response time to results of medical tests) was the area that the patients were unsatisfied with. A big part of the quality of service and patient satisfaction is the consultation time between doctors and patients. The duration of consultation time varies from one country to the other due to patient's and doctor's characteristics [17]. In a study done in Malaysia, Ahmad, Hhairatul, and Farnaza found that the average consultation time for their study was 18.21 minutes [17]. In the health centre used for this study, the consultation time based on the online scheduling system is 15 minutes.

The review of the literature also showed others studies done on health issues and service utilization of university students [18]; health problems with college students [19]; issues in university health services [20]; and the use of medicine by university students in Mozambique [21]. Other studies include Wise [22] which examined patient utilisation of student health services at the University of North Carolina. This study focused on the factors that influenced students' attitudes towards the services provided at the student health centre [22]. El-Gilany, El-Masry and Badwy investigated students' utilisation of health services at the Mansoura University in Egypt [23]. The main focus was on patterns of morbidity and drug prescription among patients. Regarding the integration of health centre and pharmacy services, [24] and [25] are some of the scholars who have written on this topic. In a commentary by Inguanti [24], it was noted that pharmacy services located in health centres play an important role in providing services within the same location since they offer a one-stop service at a reduced cost to the patients. Such health centres, are noted "focus on meeting the basic health care needs of their individual communities" [24] (p. 151). On the other hand, Wright, Gorman, Odorzynski, Peterson et al. investigated the potential benefits of having a pharmacy within mental health centres in Michigan, in the United States [25]. Their findings showed that patients using pharmacies located within the proximity to the source of prescription had better adherence to medication, and also found it to be cheaper.

The review of the literature clearly shows the need for more studies on health care units within higher education institutions to be studied in the Caribbean. This paper is designed to fill this gap in the existing literature. In this study online appointment system and online scheduling system are used interchangeable.

\subsection{Statement of the Problem}

The practice before the online scheduling system was established was that the users of the health centre walked-in to schedule appointments before they could access the health care services. Furthermore, the old system was based on first come first served, which resulted in users lining up very early to write their names, and the arrival time in the registration book at the reception area or desk. The quality of service as it relates to the speed of registration and patient flow 
was slow and patients also experienced the long waiting time before seeing the doctor. Aware of the challenges of manual registration method, the university's management introduced an online system for scheduling appointments in 2014. With this system, patients can select the date and time they would like to see the doctor, as well as select other services provided at the health centre, and the health centre staff can access the medical records ahead of the patient's visit.

Since the launch of the online scheduling system for booking appointment, there has not been any study to document the users' views on the system. This study was designed to provide evidence on the users' views of the online scheduling system, its benefits and challenges. It is believed that the findings of this study will contribute to the existing body of literature on this topic as well as to lead to the improvement of the online scheduling system.

\subsection{Research Questions}

The following research questions were answered:

1) What are the views of the users about the online scheduling system?

2) To what extent are there differences in the views of the different groups of users (students vs staff \& males vs females) about the services provided at the health centre?

3) What suggestions, if any, could be made on how to improve the online scheduling system and services at the health centre?

Only 50 users' views on the online scheduling system and health services provided were investigated. Therefore, the findings cannot be generalised.

\subsection{Description of Study Setting}

The then College of Arts, Science and Technology (CAST), now the University of Technology (UTech), Jamaica opened its first health centre in 1971. Initially, the Health Centre had a visiting doctor, a college nurse and a nurse manager [26]. As the university expanded, there was a need in 2001, to relocate the centre to a bigger space, in order to accommodate the growing demand for health services on campus. This expansion also included increasing the staff strength. Currently, the staff strength is nine medical doctors (i.e., 2 full-time \& 7 part-time), seven nurses ( 4 full-time $\& 6$ part-time), an administrator, and one claims clerk.

During each academic year over 2,000 students and staff members visited the health centre. Because the lifestyles of staff and students are considered to be important, the medical health centre offer services that promote health and wellness among staff and students through seminars, lab result review, medicals, wound care, family planning, counselling, etc. [26].

\section{Methods}

\subsection{Design and Sample}

A descriptive research design was used for the study to assess the users' views on 
an online appointment system and services provided at a university health centre in Jamaica during the 2016/17 academic year. The convenience sampling method was used to select the study participants $(n=50)$ who visited the university health centre during that academic year. Consequently, there was no need for power calculation of the sample size.

\subsection{Data Collection}

Data were collected through the use of a questionnaire. The questionnaire had three sections. Section A contained four demographic items, while Section B had six items on the online scheduling system and one open-ended question on how to improve the online scheduling system. Section C contained 13 Likert-type items on health services. These items had a four-point response format of strongly disagree to strongly agree.

\subsection{Data Analysis}

The Statistical Package for the Social Sciences (SPSS), version 21 was used to analyse the close-ended items, while the Excel program was used for the openended item. This program was used because it was easier to identify the individual responses before organizing them into categories. For the close-ended items, descriptive statistics (simple percentage \& cross-tabulation) was used for research questions one and two due to the nature of the questions asked. However, the Fisher's Exact Test $(2 \times 2$ contingency table) was also used for research question two in order to ascertain if there was any statistical difference in the respondents' views. This was done to avoid generating misleading results due to the small number of observations per cell [27].

\subsection{Reliability and Validity}

The Cronbach's alpha method was used in estimating the reliability of the $13 \mathrm{Li}$ kert-type items in Section C of the questionnaire. The obtained reliability coefficient was 0.87 , which is considered to be highly reliable [28] [29]. Content validity was established by using three experts to review the questionnaire items. This is to ensure that the items were about the online scheduling system and the health services.

\subsection{Ethical Issues}

This study falls under the health service evaluation category. The National Research Ethics Service (NRES) states that studies that are categorised under service evaluation are "designed and conducted solely to define or judge current care" [30]. This study, therefore, did not require research ethics review. However, several ethical practices were observed. For instance, the participants were not forced to take part in the study. Only those who consented completed the questionnaire. Names, as well as identification of the participants, were not collected. 


\section{Results}

The results are presented under four themes, namely, comparing demographic characteristics, comparing users' views on online scheduling system, comparing users views on online scheduling and health centre services, and improve the online scheduling system and services.

\subsection{Comparing Demographic Characteristics}

To have an insight about the respondents in this study, demographic information, including gender, age range and status was collected through the use of a questionnaire. The data were analysed using cross-tabulation (Table 1). A total of $14(28.0 \%)$ males and $36(72.0 \%)$ females participated in the study. The findings showed that $30(60.0 \%)$ of the respondents were between the ages of $21-30$ years. Thirty $(60.0 \%)$ of the respondents were students and $20(40.0 \%)$ staff members who had visited the health centre during the period the study was conducted.

\subsection{Comparing Users Views on Online Scheduling System}

Research Question One: What are the views of the users about the online scheduling system?

Regarding research question one, the respondents were asked to indicate if they were visiting the health centre for the first time. Of the 50 respondents, four or eight percent were visiting for the first time, while 46 (92.0\%) had made several visits to the centre, and had also used the online scheduling system to book appointments. The respondents were asked to indicate how they find out about the online scheduling system. Of the 46 respondents who used the health centre previously, 12 (9.1\%) learnt of it through the university email, five $(11.4 \%)$ through a colleague, another five (11.4\%) through a friend, and $22(50.0 \%)$ through the health centre staff. The 46 respondents commented on how satisfied they are with the use of the online scheduling system (Table 2).

Table 1. Demographic characteristics of participants.

\begin{tabular}{cccc}
\hline Variables & Students $(\mathrm{n}=30)$ & Staff $(\mathrm{n}=20)$ & Total \\
\hline Gender & $10(20.0 \%)$ & $4(8.0 \%)$ & $14(28.0 \%)$ \\
Male & $20(40.0 \%)$ & $16(32.0 \%)$ & $36(72.0 \%)$ \\
Female & $6(12.0 \%)$ & & \\
Age Range & $22(44.0 \%)$ & $8(16.0 \%)$ & $30(12.0 \%)$ \\
$\leq 20$ years & 0 & $5(10.0 \%)$ & $5(10.0 \%)$ \\
$21-30$ years & $1(2.0 \%)$ & $6(12.0 \%)$ & $7(14.0 \%)$ \\
$31-40$ years & $1(2.0 \%)$ & $1(2.0 \%)$ & $2(4.0 \%)$ \\
$41-50$ years & & & \\
$\geq 50$ years & & & \\
& & & \\
\end{tabular}


Table 2. Respondents' rating of the adequacy of the online scheduling system.

\begin{tabular}{cccc}
\hline Responses & Students $(\mathrm{n}=30)$ & Staff $(\mathrm{n}=20)$ & Total \\
\hline Not at all Satisfied & $1(2.2 \%)$ & $1(2.2 \%)$ & $2(4.3 \%)$ \\
Somewhat Satisfied & $8(17.4 \%)$ & $1(2.2 \%)$ & $9(19.6 \%)$ \\
Satisfied & $13(28.3 \%)$ & $8(17.4 \%)$ & $21(45.7 \%)$ \\
Very Satisfied & $7(15.2 \%)$ & $7(15.2 \%)$ & $14(30.4 \%)$ \\
Total & $29(63.0 \%)$ & $17(37.0 \%)$ & $46(100.0 \%)$ \\
\hline
\end{tabular}

No response $(\mathrm{NR})=4$.

As shown in Table 2, 30 (65.3\%) of the respondents rated the online scheduling system between "Somewhat Satisfied" and "Satisfied." When the data were also analysed by gender, the result was the same. Thirty-eight (82.6\%) of those who were satisfied, also indicated that it was user-friendly.

\subsection{Comparing Users Views on Online Scheduling and Health Centre Services}

Research Question Two: To what extent are there differences in the views of the different groups of users (students vs staff \& males vs females) about the staff and the services provided at the health centre?

Regarding research question two, 13 Likert-type items were used to obtain the respondents' views on the staff and the health services. For each of the statements listed in Table 3, respondents were given answer choices of "Strongly Agree," "Agree," "Disagree," and "Strongly Disagree." It should be noted that "Neither" response was not offered.

The findings in Table 3 showed that 46 (92.0\%) of the students and the staff agreed that the health center offers a sufficient variety of services; 47 (94.0\%) had the same opinion that the services met their health needs; 37 (\%) concurred that the services offered were always available; 49 (98.0\%) were satisfied with the services provided by the nurses; 45 (90.0\%) were satisfied with the level of care displayed by the nurses, and 49 (98.0\%) of the students and the staff were satisfied with the level of care displayed by the doctors; and $40(80.0 \%)$ also were satisfied with the services provided by the doctors; 41 (82.0\%) were in agreement that the waiting time was reasonable; $42(84.0 \%)$ were comfortable with the level of privacy and confidentiality; $43(86.0 \%)$ agreed that with the online scheduling they had enough time with the doctor; $32(64.0 \%)$ were also in agreement that they were clear about the procedure to be followed when accessing the different services offered at the health centre; $39(78.0 \%)$ agreed that with the online scheduling, there is an improved customer service; and 42 (84.0\%) were satisfied with the overall customer service.

To compare the samples on agreement, the four-point responses were recoded into two categories ("Agree" \& "Disagree"). See Table 3 for the results of the Fisher Exact test. As shown in Table 3, the students and staff displayed differences in their responses to two items, "I am satisfied with the services provided 
Table 3. Comparing users views on online scheduling and health centre services.

\begin{tabular}{|c|c|c|c|c|c|}
\hline \multirow{2}{*}{ Items } & \multicolumn{2}{|c|}{ Students $(\mathrm{n}=30)$} & \multicolumn{2}{|c|}{ Staff $(\mathrm{n}=20)$} & \multirow{2}{*}{$P$-value } \\
\hline & Disagree & Agree & Disagree & Agree & \\
\hline $\begin{array}{l}\text { The health center offers } \\
\text { a sufficient variety of services }\end{array}$ & $\begin{array}{c}3 \\
(10.0 \%)\end{array}$ & $\begin{array}{c}27 \\
(90.0 \%)\end{array}$ & $\begin{array}{c}1 \\
(5.0 \%)\end{array}$ & $\begin{array}{c}19 \\
(95.0 \%)\end{array}$ & 0.64 \\
\hline $\begin{array}{l}\text { The services meet } \\
\text { my health needs }\end{array}$ & 0 & $\begin{array}{c}30 \\
(100.0 \%)\end{array}$ & $\begin{array}{c}3 \\
(15.0 \%)\end{array}$ & $\begin{array}{c}17 \\
(85.5 \%)\end{array}$ & 0.06 \\
\hline $\begin{array}{l}\text { The services offered } \\
\text { are always available }\end{array}$ & $\begin{array}{c}7 \\
(23.3 \%)\end{array}$ & $\begin{array}{c}23 \\
(76.7 \%)\end{array}$ & $\begin{array}{c}6 \\
(30.0 \%)\end{array}$ & $\begin{array}{c}14 \\
(70.0 \%)\end{array}$ & 0.74 \\
\hline $\begin{array}{l}\text { I am satisfied with the services } \\
\text { provided by the nurses }\end{array}$ & $\begin{array}{c}1 \\
(3.3 \%)\end{array}$ & $\begin{array}{c}29 \\
(96.7 \%)\end{array}$ & 0 & $\begin{array}{c}20 \\
(100.0 \%)\end{array}$ & 1.00 \\
\hline $\begin{array}{l}\text { I am satisfied with the level of } \\
\text { care displayed by the nurses }\end{array}$ & $\begin{array}{c}4 \\
(13.3 \%)\end{array}$ & $\begin{array}{c}26 \\
(86.7 \%)\end{array}$ & $\begin{array}{c}1 \\
(5.0 \%)\end{array}$ & $\begin{array}{c}19 \\
(95.0 \%)\end{array}$ & 0.64 \\
\hline $\begin{array}{l}\text { I am satisfied with the services } \\
\text { provided by the doctors }\end{array}$ & $\begin{array}{c}1 \\
(3.3 \%)\end{array}$ & $\begin{array}{c}29 \\
(96.7 \%)\end{array}$ & $\begin{array}{c}9 \\
(45.0 \%)\end{array}$ & $\begin{array}{c}11 \\
(55.0 \%)\end{array}$ & $0.01^{*}$ \\
\hline $\begin{array}{l}\text { I am satisfied with the level of } \\
\text { care displayed by the doctors }\end{array}$ & $\begin{array}{c}1 \\
(3.3 \%)\end{array}$ & $\begin{array}{c}29 \\
(96.7 \%)\end{array}$ & 0 & $\begin{array}{c}20 \\
(100.0 \%)\end{array}$ & 1.00 \\
\hline $\begin{array}{l}\text { With online scheduling, the waiting } \\
\text { time is reasonable }\end{array}$ & $\begin{array}{c}6 \\
(20.0 \%)\end{array}$ & $\begin{array}{c}24 \\
(80.0 \%)\end{array}$ & $\begin{array}{c}3 \\
(15.0 \%)\end{array}$ & $\begin{array}{c}17 \\
(85.5 \%)\end{array}$ & 0.72 \\
\hline $\begin{array}{l}\text { I feel comfortable with the level } \\
\text { of privacy and confidentiality }\end{array}$ & $\begin{array}{c}5 \\
(16.7 \%)\end{array}$ & $\begin{array}{c}25 \\
(83.3 \%)\end{array}$ & $\begin{array}{c}3 \\
(15.0 \%)\end{array}$ & $\begin{array}{c}17 \\
(85.5 \%)\end{array}$ & 1.00 \\
\hline $\begin{array}{l}\text { With online scheduling, I still } \\
\text { get enough time with the doctor }\end{array}$ & $\begin{array}{c}4 \\
(13.3 \%)\end{array}$ & $\begin{array}{c}26 \\
(86.7 \%)\end{array}$ & $\begin{array}{c}3 \\
(15.0 \%)\end{array}$ & $\begin{array}{c}17 \\
(85.5 \%)\end{array}$ & 1.00 \\
\hline $\begin{array}{l}\text { I am clear about the procedure } \\
\text { to access the different services }\end{array}$ & $\begin{array}{c}15 \\
(50.0 \%)\end{array}$ & $\begin{array}{c}15 \\
(50.0 \%)\end{array}$ & $\begin{array}{c}3 \\
(15.0 \%)\end{array}$ & $\begin{array}{c}17 \\
(85.5 \%)\end{array}$ & $0.02^{*}$ \\
\hline $\begin{array}{l}\text { With online scheduling, } \\
\text { there is improved customer service }\end{array}$ & $\begin{array}{c}7 \\
(23.3 \%)\end{array}$ & $\begin{array}{c}23 \\
(76.7 \%)\end{array}$ & $\begin{array}{c}4 \\
(20.0 \%)\end{array}$ & $\begin{array}{c}16 \\
(80.0 \%)\end{array}$ & 1.00 \\
\hline $\begin{array}{l}\text { I am satisfied with the } \\
\text { overall customer service }\end{array}$ & $\begin{array}{c}7 \\
(23.3 \%)\end{array}$ & $\begin{array}{c}23 \\
(76.7 \%)\end{array}$ & $\begin{array}{c}1 \\
(5.0 \%)\end{array}$ & $\begin{array}{c}19 \\
(95.0 \%)\end{array}$ & 0.12 \\
\hline
\end{tabular}

${ }^{\star} P<0.05$.

by the doctors" ( $p=0.01)$, and "I am clear about the procedure to access the different services" $(p=0.02)$. The association between the two samples is considered to be statistically significant. However, no significant differences were found in the other 11 items between the two groups.

\subsection{Improve the Online Scheduling System and Services}

Research Question Three: What suggestions, if any, could be made on how to improve the online scheduling system and services at the health centre? Four themes (appointment efficiency, walk-in and online scheduling system, linking health centre service with pharmacy, time management, \& educating the users) emerged from the analysis of the responses to the open-ended question on suggestions on how to improve online scheduling system and services. The findings are presented under the themes mentioned above. 


\subsubsection{Appointment Efficiency}

Several views were expressed about the efficiency of booking of appointment as some of the respondents expected that with the online scheduling system, their appointment with the doctor would be on time. However, their experiences reflected otherwise. Here are some of the suggestions made by the respondents:

- Using the online scheduling system, I was of the view that I will be seeing the doctor on time, but this is not the case. This system only allows you to indicate that you will be seeing a doctor. The doctors need to ensure that the patients get service on time. (Female student, 21 - 30 years)

- The doctors sometimes arrive late or are behind time in seeing the patients. The nurses and doctors should consult within the time frame booked by the patients. (Male, staff, 41 - 50 years)

\subsubsection{Walk-in and Online Scheduling System}

Some of the respondents were not of the view that both the online scheduling system and the walk-in method should be used in the health centre. This omission of information was reflected in their suggestions. It should be pointed out that both the online scheduling system and the walk-in method are used. However, the latter is usually done to accommodate emergency cases. Here are some of the comments made by the respondents:

- I need to be able to see a doctor through the walk-in method. (Female staff, 41 - 50 years)

- It will be nice to accept walk-in patients also. (Female staff, 31 - 40 years)

\subsubsection{Linking Health Centre Service with Pharmacy}

Currently, the practice is that patients physically take their prescriptions to the pharmacy which is located elsewhere on campus. Some patients are of the view that the services provided by the two units should be linked together. Stated below is the suggestion made by a respondent.

- The doctors could send the prescriptions to the UTech's pharmacy, which would make the filling of the prescription faster. The pharmacy service is very slow, and this increases the waiting time before getting the medication.

(Female student, $\geq 50$ years).

\subsubsection{Time Management}

Some of the respondents were of the view that there is a time management problem with the online scheduling system. They are of the view that with more doctors, the consultation time could be managed properly. Hence the suggestions made below.

- At times, there are available time slots, but there are no doctors. Engage the services of more doctors and try to allocate more appointment spaces for customers, if possible. (Male student, $\leq \mathbf{2 0}$ years)

- There is a need to get more doctors on board and standardise the amount of time the doctors spend with a patient. (Female student, 21 - 30 years)

- In the study conducted by Braddock and Snyder, they stated ethical obliga- 
tions should guide physicians about time management [31]. They added that "as such, judging the adequacy of time in clinical practice requires that we call on the ethical principles and values inherent in medicine" [31] (p. 1056).

\subsubsection{Educating the Users}

Some of the respondents were of the view that more information about the health centre and its services should be provided. Hence, some have made suggestions on how to disseminate this information to the users.

- Not everyone is familiar with the acronym on the website as it relates to the online scheduling. There is a need to make the information clearer on the university website. (Male student, 21 - 30 years)

- Place notices around the campus to make users more aware (Male student, 21 - 30 years)

- Have a worksheet instruction flyer on how to use the online scheduling system, and make it more user-friendly. (Female student, 31 - 40 years)

\section{Discussion of Results}

In research question one, $92.0 \%$ of the respondents had visited the health centre and had used the online scheduling system. Fifty percent of the respondents were made aware of the online system by the health centre staff; this showed that the dissemination of information about the system was limited. Cao et al. recommended the need to better promote the use of the WAS among the patients [7].

The findings showed that approximately $76.0 \%$ of those respondents who had used the online scheduling system before were either satisfied or very satisfied, and also found it to be user-friendly. This is consistent with the findings of other studies [7] [32]. Cao et al. found out that patients in primary health care clinics in Saudi Arabia and China, respectively, were satisfied with web-based/online appointment systems when compared to those who use the queuing method who experienced a longer waiting time [7]. In a study conducted in Iran involving the use of 425 women, Sadjadian, Kaviani, Yunesian, and Montazeri, they found that $82 \%$ of the women were either satisfied or very satisfied with the clinic's overall performance [12]. Furthermore, the findings are also consistent with the literature, which also found that participants in their studies were satisfied with the services provided at their health facilities showed that [4] [13] [14] [15]. On the contrary, a study by Al-Refaie in Jordanian hospitals, indicated dissatisfaction of the respondents with service quality [16].

Regarding research question two, for the 13 Likert-type items, the percentage of agreement between the students and the staff who responded were between $64.0 \%$ and $98.0 \%$. This showed that a majority were in agreement with their responses to the items.

However, there were statistically significant differences in the views expressed by the students and the staff on two items: "I am satisfied with the services provided by the doctors," and "I am clear about the procedure to access the different 
services." This was because of the mean difference. The mean for the students was $(M=3.53, S D .57)$ and $(M=3.45, S D=.76)$ for the staff for the services provided by the doctors. This finding is consistent with the study done by Panda, Sinha, and Soni in India, which showed that $49.5 \%$ of the respondents rated the services by doctors as excellent [13]. In another study by Sadjadian et al. [12], the physical environment and the doctors' consultation style were the reasons why the women's overall performance satisfaction was high. For the statement "I am clear about the procedure to access the different services," the values were $(M=2.57, S D=0.82)$ for the students and $(M=3.35, S D=0.75)$ for the staff. No study was found to support this finding.

Regarding the health centre and pharmacy services, due to lack of physical space, it will be hard to have both within a locality. In a commentary written by Inguanti [24], it was noted that pharmacy services that are located in health centres play an important role in providing services within the same location. However, in the current study, for medications that are available in the university pharmacy, the researchers support the view that doctors could send the prescriptions to the university pharmacy, which would make the filling of the prescription easier for the patients and a little cheaper. Inguanti [24], and Wright, Gorman, Odorzynski, Peterson et al. [25] acknowledged that the physical proximity of a pharmacy to a health centre tend to have a cheaper rate for the patients.

\section{Conclusions}

The online appointment system is gaining more popularity and due to its numerous benefits such as minimising waiting time, patients being able to schedule their appointment without using the walk-in method, getting email appointment schedule reminder, and among others. To some scholars, it is regarded as a win-win solution for patients and physicians. Despite its several benefits, the online scheduling system is also affected by several factors such as availability of information technology, issues with consultation time, and the experience level of the scheduling staff.

This study was designed to provide evidence on the users' views of the online scheduling system, its benefits and challenges. The findings showed that the views of the users about the online scheduling system were positive. There was a significant difference in the views of the students and staff on two of the $13 \mathrm{Li}$ kert-type items that measured the services provided at the health centre. The respondents were provided comments on how to improve the online scheduling system and services at the health centre.

Although the findings of this study cannot be generalised due to the sample size used, the results could be used to improve the online appointment system as well as other services offered at the health centre. Based on the findings of the study, the following recommendations are made:

1) Use of a bigger sample size in future studies to make it possible to generalise the findings. 
2) Ensure that more patients who continue to use the online appointment system find the experience satisfactory. This could be achieved by minimising the waiting time to see a doctor.

3) Advertise the online system not just by the health centre staff but electronically throughout the university community and also seeking suggestions on how to further improve the system.

4) Ensure that the doctors try to be on time to see patients who have already made such appointments.

5) Facilitate the patients whose prescriptions could be filled at the university pharmacy through the use of technology.

6) Engage the services of more doctors to better manage the consultation time between the doctors and their patients.

\section{Conflicts of Interest}

The authors declare no conflicts of interest regarding the publication of this paper.

\section{References}

[1] Mardiah, F.P. and Basri, M.H. (2013) The Analysis of Appointment System to Reduce Outpatient Waiting Time at Indonesia's Public hospital. Human Resource Management Research, 3, 27-33.

[2] Mahdavi, M., Parsaeian, M., Jaafarpooyan, E. and Ghaffari, S. (2018) Recent Iranian Health System Reform: An Operational Perspective to Improve Health Services Quality. International Journal of Health Policy Management, 7, 70-74. https://doi.org/10.15171/ijhpm.2017.89

[3] Cayirili, T., Yany, K.K. and Quek, S.A. (2012) A Universal Appointment Rule in the Presence of No-Shows and Walk-Ins. Production and Operations Management, 21, 682-697. https://doi.org/10.1111/j.1937-5956.2011.01297.x

[4] Andrabi, S.A., Hamid, S., Rohul, J. and Anjum, F. (2012) Measuring Patient Satisfaction: A Cross-Sectional Study to Improve Quality Care at a Tertiary Care Hospital. Health Line, 3, 59-62.

[5] Samadbeik, M., Saremian, M., Garavand, A., Hasanvandi, A., Sanaeinasag, A. and Tahmasebi, H. (2018) Assessing the Online Outpatient Booking System. Shiraz E Medical Journal, 19. e60249.

[6] Pare, G., Trudel, M.C. and Forget, P. (2014) Adoption, Use, and Impact of e-Booking in Private Medical Practices: Mixed-Methods Evaluation of a Two-Year Showcase Project in Canada. JMIR Medical Informatics, 2, e24.

https://doi.org/10.2196/medinform.3669

[7] Cao, W., Wan, Y., Tu, H., Shang, F., Liu, D., Tan, Z., Sun, C., Ye, Q. and Xu, Y. (2011) A Web-Based Appointment System to Reduce Waiting for Patients: A Retrospective Study. BMC Health Services Research, 11, 318. https://doi.org/10.1186/1472-6963-11-318

[8] Ellingsen, G. and Obstfelder, A. (2006) Collective Expectations-Individual Action Implementing Electronic Booking Systems in Norwegian Health Care. International Medical Informatics, 76, 104-112. https://doi.org/10.1016/j.ijmedinf.2006.05.029

[9] Nazia, S. and Sarda, E. (2014) Online Appointment Scheduling System for Hospit- 
als-An Analytical Study. International Journal of Innovations in Engineering \& Technology, 4, 21-27.

[10] Irin Sherly, I., Mahalakshi, A., Menaka, D. and Sujatha, R. (2016) Online Appointment Reservation and Scheduling for Healthcare: A Detailed Study. International Journal of Innovative Research in Computer \& Communication Engineering, 4, 2053-2059.

[11] Zhang, M., Zhang, C., Sun, Q., Cai, Q., Yang, H. and Zhang, Y. (2014) Questionnaire Survey about Use of an Online Appointment Booking System in One Large Tertiary Public Hospital Outpatient Service Center in China. BMC Medical Informatics and Decision Making, 14.

[12] Sadjadian, A., Kaviani, A., Yunesian, M. and Montazeri, A. (2004) Patients Satisfaction: A Descriptive Study of a Breast Care Clinic in Iran. European Journal of Cancer Care, 12, 163-168. https://doi.org/10.1111/j.1365-2354.2004.00459.x

[13] Panda, P. S., Sinha, A. K. and Soni G. P. (2018) Level of Satisfaction of Patients Attending Out-Patient Department of Radiotherapy Department of a Tertiary Hospital in Raipur, Chhattisgarh, India. International Journal of Research in Medical Sciences, 6, 922-927. https://doi.org/10.18203/2320-6012.ijrms20180616

[14] Al-Abri, R. and Al-Balushi, A. (2014) Patient Satisfaction Survey as a Tool towards Quality Improvement. Oman Medical Journal, 29, 3-7. https://doi.org/10.5001/omj.2014.02

[15] Arhad, S., Andrabi, H., Hamid, S. and Masooda, S. (2012) Measuring Patient Satisfaction: A Cross-Sectional Study to Improve Quality Care at a Tertiary Care Hospital. East African Journal of Public Health, 9, 26-28.

[16] Al-Refaie, A. (2011) A Structural Model to Investigate Factors Affecting Patient Satisfaction and Revisit Intention in Jordanian Hospitals. International Journal of Artificial Life Research, 2, 43-56. https://doi.org/10.4018/jalr.2011100105

[17] Ahmad, B.A., Hhairatul, K. and Farnaza, A. (2017) An Assessment of Patient Waiting and Consultation Time in a Primary Healthcare Clinic. Malaysian Family Physician, 12, 14-21.

[18] Fletcher, P.C., Bryden, P.J., Schneider, M.A., Dawson, K.A. and Vandermeer, A. (2007) Health Issues \& Service Utilization of University Students: Experiences, Practices, and Perceptions of Students, Staff and Faculty. College Student Journal, 41, 482-493.

[19] Grace, W.T. (1997) Health Problems of College Students. Journal AM College Health, 45, 243-250. https://doi.org/10.1080/07448481.1997.9936894

[20] Meilman, P. (2001) Human Resource Issues in University Health Services. Journal AM College Health, 50, 43-47. https://doi.org/10.1080/07448480109595711

[21] Lucas, R., Lunet, N. and Carvalho, R. (2007) Patterns in the Use of Medicine by University Students in Maputo, Mozambique. Cadernos de Saúde Pública, 23, 2845-2852. https://doi.org/10.1590/S0102-311X2007001200005

[22] Wise, A.L. (n.d.) Patient Utilization of Student Health. https://lamandalwise.files.wordpress.com/2014/09/pa

[23] El-Gilany, A.H., El-Masry, R. and Badawy, K. (2014) Students' Utilization of Health Services: A Hospital-Based Study in Mansoura University, Egypt. European Journal of General Medicine, 11, 221-229. https://doi.org/10.15197/sabad.1.11.76

[24] Inguanti, M. (2011) Community Health Centers: A Pharmacist's Perspective. The American Journal of Pharmacy Benefits, 150-151.

http://www.fchcstl.org/pdf/_AJPB_11jun_FQCHC.pdf 
[25] Wright, W.A., Gorman, J.M., Odorzynski, M., Peterson, M.J. and Clayton, C. (2016) Integrated Pharmacies at Community Mental Health Centers: Medication Adherence and Outcomes. Journal of Managed Care \& Specialty Pharmacy, 22, 1330 1336. https://www.jmcp.org/doi/pdf/10.18553/jmcp.2016.16004 https://doi.org/10.18553/jmcp.2016.16004

[26] University of Technology, Jamaica Health Centre (n.d.) Medical Health Centre Document.

[27] Bower, K.M. (n.d.) When to Use Fisher's Exact Test. http://staff.ustc.edu.cn/ Zwp/teach/nonpar/fisher_exact_test.pdf

[28] Bryman, A. and Cramer, D. (2011) Quantitative Data Analysis with SPSS 17, 18 and 19: A Guide for Social Scientists. Routledge, London.

[29] Morgan, G.A., Leech, N.L., Gloeckner, G.W. and Barrett, K.C. (2007) SPSS for Introductory Statistics: Use and Interpretation. 3rd Edition, Psychology Press, New York.

[30] Health Research Authority (2013) Defining Research. https://researchsupport.admin.ox.ac.uk/sites/default/files/researchsupport/docume nts/media/defining-research.pdf

[31] Braddock, C.H. and Snyder, L. (2005) The Doctor Will See You Shortly: The Ethical Significance of Time for the Patient-Physician Relationship. Journal of General Internal Medicine, 20, 1057-1062. https://doi.org/10.1111/j.1525-1497.2005.00217.x

[32] Ali-Haqwi, A.I. and Al-Shehri, A.M. (2007) Appointment System in Primary Care: Opinion of Consumers and Providers. Journal of Family and Community Medicine, 14, 99-102. 